\title{
The effect of wheat prebiotics on the gut bacterial population and iron status of iron deficient broiler chickens
}

\author{
Elad Tako ${ }^{1}$, Raymond P Glahn ${ }^{1}$, Marija Knez ${ }^{2^{*}}$ and James CR Stangoulis ${ }^{2}$
}

\begin{abstract}
Background: Currently, there is a lot of interest in improving gut health, and consequently increasing Fe absorption, by managing the colonic microbial population. This is traditionally done by the consumption of probiotics, live microbial food supplements. However, an alternative, and often very effective approach, is the consumption of food ingredients known as prebiotics. Fructans and arabinoxylans are naturally occurring non-digestible oligosaccharides in wheat that exhibit prebiotic properties and may enhance intestinal iron (Fe) absorption. The aim of this study was to assess the effect of prebiotics from wheat on Fe bioavailability in vitro (Caco-2 cells) and in vivo (broiler chickens, Gallus gallus).

Methods: In the current study, the effect of intra-amniotic administration of wheat samples extracts at $17 \mathrm{~d}$ of embryonic incubation on the Fe status and possible changes in the bacterial population in intestinal content of broiler hatchlings were investigated. A group of 144 eggs were injected with the specified solution (1 $\mathrm{ml}$ per egg) into the amniotic fluid. Immediately after hatch $(21 \mathrm{~d})$ and from each treatment group, 10 chicks were euthanized and their small intestine, liver and cecum were removed for relative mRNA abundance of intestinal Fe related transporters, relative liver ferritin amounts and bacterial analysis of cecal content, respectively.

Results: The in vivo results are in agreement with the in vitro observations, showing no differences in the hatchling Fe status between the treatment groups, as Fe bioavailability was not increased in vitro and no significant differences were measured in the intestinal expression of DMT1, Ferroportin and DcytB in vivo. However, there was significant variation in relative amounts of bifidobacteria and lactobacilli in the intestinal content between the treatments groups, with generally more bifidobacteria being produced with increased prebiotic content.

Conclusions: In this study we showed that prebiotics naturally found in wheat grains/bread products significantly increased intestinal beneficial bacterial population in Fe deficient broiler chickens. With this short-term feeding trial we were not able to show differences in the Fe-status of broilers. Nevertheless, the increase in relative amounts of bifidobacteria and lactobacilli in the presence of wheat prebiotics is an important finding as these bacterial populations may affect Fe bioavailability in long-term studies.
\end{abstract}

Keywords: Prebiotics, Arabinoxylan, Probiotics, Iron bioavailability, Chicken, Caco-2 cells

\footnotetext{
* Correspondence: marijaknez186@gmail.com

${ }^{2}$ School of Biological Sciences, Flinders University, GPO Box 2100, Adelaide, SA 5001, Australia

Full list of author information is available at the end of the article
} 


\section{Introduction}

Micronutrient malnutrition, often called 'hidden hunger', is a serious health problem worldwide. The most prevalent micronutrient deficiency is iron (Fe) deficiency, affecting about $40 \%$ of the world's population, particularly women and children in developing countries [1,2]. Cereal crops are an important source of minerals and other nutrients for humans. Wheat is currently the primary staple food for nearly one-third of the world's population, providing $>50 \%$ of the total daily energy intake [3]. Wheat grains contain significant amounts of dietary fiber and phytate.

It is believed that diets high in phytate contribute to Fe deficiency $[4,5]$. In contrast, some naturally occurring non-digestible oligosaccharides in wheat, known as prebiotics, have been suggested to have an enhancing effect on Fe absorption [6,7].

Prebiotics have the ability to support the growth of probiotics $[8,9]$. The fermentation of prebiotics by colonic bacteria gives rise to production of unbranched SCFA such as acetic, propionic, butyric, and lactic acids, thereby lowering intestinal $\mathrm{pH}[10,11]$, inhibiting the growth of potentially harmful bacteria [11] and improving mineral absorption [12-15]. Next to inulin and fructo-oligosaccharides (FOS), the two most extensively studied prebiotics, arabinoxylans (AXs) are also considered as a potential new class of prebiotic components [16]. AXs are present mainly in the bran portion, for example in wheat bran (6.7\%). However, the thin aleurone layer surrounding wheat endosperm contains $60-70 \%$ AX [17]. Overall, they constitute $60-69 \%$ of non-starch polysacharides in wheat bran [18] and $88 \%$ in wheat endosperm [19].

Inulin and FOS have been shown several times to selectively stimulate bifidobacteria [20-22,7]. Regarding the absorption of $\mathrm{Fe}$, it has recently been shown that intra-amniotic administration and dietary inulin improved the Fe status of Fe deficient broilers [9]. mRNA abundance of DMT1 and ferroportin in addition to liver ferritin were higher in the inulin group compared to control $(\mathrm{p}<0.05)$ [9]. Similarly, Yasuda et al. [15] demonstrated improvement in hemoglobin repletion efficiency in young anemic pigs fed corn soybean meal supplemented with $4 \%$ dietary inulin. Recently, Freitas et al. [23] showed the benefit of inulin and oligofructose prebiotics on the regeneration of haemoglobinic mass and increased intestinal Fe absorption in anaemic rats. However, to date, the comparison of the effect of prebiotics (with different fructan and arabinoxylan content) both from raw and processed wheat on Fe absorption has not been investigated.

Therefore, the primary aim of this study was to assess the effect of prebiotics from wheat on short-term Fe bioavailability in-vitro (in Caco-2 cells) and in-vivo (broiler chickens). Within this aim there were several objectives: (A) to compare the effect of wheat treatments with varied arabinoxylan and fructan content on Fe availability and (B) to evaluate the differences in the efficacy of prebiotics from processed and unprocessed wheat grain flour. Finally, in view of the fact that people do not consume raw cereal grains and that processing and baking are common practices worldwide, our last objective was (C) to examine the effect of prebiotics from baked wheat products (breads baked for $45 \mathrm{~min}$ and $5 \mathrm{~min}$ ) on Fe status and gut microbiata of iron deficient broilers hatchlings.

\section{Materials and methods}

\section{Wheat and bread samples}

The four samples of double haploid lines included in this study were from the Berkut $\times$ Krichauff doubled haploid (DH) population, previously used to map quantitative trait loci (QTL) for high AX in this population [24]. The population was grown in 2009 at Roseworthy in South Australia, at an adequate-rainfall site. The lines were chosen based on their fructan and arabinoxylan content (the lines with the highest and the lowest fructan and arabinoxylan amounts were included). These samples were compared with commercially bought white and wholemeal flour mixes and their baked products (Laucke Flour Mills; www.laucke. com.au).

\section{Bread and chapatti sample preparation}

Bread loaves (1 kg, standard size) were baked using an automatic bread maker Breville BBM100 (Sydney, Australia). An identical baking program was established for the preparation of all breads.

The endpoint of baking was set as "Medium Crust." The total baking time was $3 \mathrm{~h}$ and $5 \mathrm{~min}$, including 25 min kneading, $1 \mathrm{~h}$ and 40 min fermentation and $1 \mathrm{~h}$ baking at $155^{\circ} \mathrm{C}$.

The average amount of the flour mix used for preparation of a loaf of bread was $600 \mathrm{~g}$.

Weight of other ingredients (yeast and water) was $420 \mathrm{~g}$ for white and $550 \mathrm{~g}$ for wholemeal bread. Once the baking was completed bread loaves were removed from the oven, left to cool on a rack and subsequently frozen to $-25^{\circ} \mathrm{C}$.

Chapatti breads were prepared using $120 \mathrm{~g}$ of the flour mix and $80 \mathrm{ml}$ of water. Dough was kneaded by hand for $20 \mathrm{~min}$ than left to rest for a further $30 \mathrm{~min}$ (room temperature) before cooking. The dough was shaped into a flat 6-inch disc and cooked on a hot skillet (Sunbeam Classic Skillet SK 4200P $25 \mathrm{~cm} ; 210^{\circ} \mathrm{C}$ ) for 1-2 min until brown spots formed on both sides of the dough. Cooked chapatti was left to cool to room temperature and put at $-25^{\circ} \mathrm{C}$ freezer.

The samples (both yeast leavened and chapatti breads) were freeze-dried for $48 \mathrm{~h}$ (Dynavac freeze drying unit) to remove all moisture before grinding (Retch 2M1000b; 
Retch, Ochten, The Netherlands). All milled samples were stored in plastic containers at room temperature until analysis.

\section{Sugar, phytate and micronutrient analyses}

Sugar and phytate analyses were performed using High Performance Liquid Chromatography (HPLC) on a Dionex ICS-3000 unit as described by Huynh et al. [25] for fructans, Nguyen et al. [24] for AXs and by Lehrfeld et al. [5] for phytate. The micronutrient concentration of samples was determined by inductively coupled plasma optical emission spectrometry (ICP-OES) [26] using an ARL 35B ICP analyser.

\section{Extraction of the wheat samples}

Procedure was conducted as previously described by Vidanarachchi et al. [27]. Briefly, the wheat exudate was dissolved in distilled water $(50 \mathrm{~g} / \mathrm{L})$ and the solution was filtered through a $600 \mu \mathrm{m}$ screen to remove particulate matter and then centrifuged at $12,000 \mathrm{~g}$ for $10 \mathrm{~min}$ at $4^{\circ} \mathrm{C}$. The supernatant was collected and dialysed (MWCO 12-14 kDa, Medicell International Ltd., London, UK) exhaustively against distilled water $(48 \mathrm{~h})$. The dialysate was collected and then lyophilized to yield a fine offwhite powder (wheat extract). In addition, in order to avoid embryonic dehydration, the samples were diluted prior to in-ovo injections (solution concentration was not higher than 320 OSM).

\section{In vitro iron bioavailability assessment}

An in vitro digestion/Caco-2 cell culture model [28] was used to assess in vitro Fe bioavailability. With this method, bread/flour samples $(0.5 \mathrm{~g})$ were subjected to simulated gastric and intestinal digestion.

Briefly, the intestinal digestion is carried out in cylindrical inserts closed on the bottom by a semipermeable membrane and placed in wells containing Caco- 2 cell monolayers bathed in culture medium. The upper chamber was formed by fitting the bottom of Transwell insert ring (Corning) with a $15000 \mathrm{Da}$ molecular weight cut off (MWCO) membrane (Spectra/Por 2.1, Spectrum Medical, Gardena, CA). The dialysis membrane was held in place using a silicone ring (Web Seal, Rochester, NY).

Iron uptake by the cell monolayers was assessed by measuring ferritin concentrations in the cells. Three replicates of each Fe bioavailability measurement were performed, each utilizing a separate sample of the wheat extract.

In terms of materials for the study, Caco-2 cells were obtained from the American Type Culture Collection (Rockville, MD) at passage 17 and used in experiments at passage 29. Cells were seeded at densities of 50,000 cells/ $\mathrm{cm} 2$ in collagen-treated 6 well plates (Costar Corp., Cambridge, MA). The integrity of the monolayer was verified by optical microscopy. The cells were cultured at $37^{\circ} \mathrm{C}$ in an incubator with $5 \% \mathrm{CO} 2$ and $95 \%$ air atmosphere at constant humidity, and the medium was changed every $48 \mathrm{~h}$.

The cells were maintained in Dulbecco's modified Eagle medium plus, $25 \mathrm{mmol} / \mathrm{L}$ HEPES, and 10\% fetal bovine serum. $48 \mathrm{~h}$ prior the experiment, the growth medium was removed from culture wells, the cell layer was washed, and the growth medium was replaced with minimum essential media (MEM) at $\mathrm{pH}$ 7.0.

The MEM was supplemented with $10 \mathrm{mmol} / \mathrm{L}$ PIPES, $1 \%$ antibiotic/antimycotic solution, $4 \mathrm{mg} / \mathrm{L}$ hydrocortisone, $5 \mathrm{mg} / \mathrm{L}$ insulin, $5 \mu \mathrm{g} / \mathrm{L}$ selenium, $34 \mu \mathrm{g} / \mathrm{L}$ triiodothyronine, and $20 \mu \mathrm{g} / \mathrm{L}$ epidermal growth factor. This enriched MEM contained less than $80 \mu \mathrm{g} \mathrm{Fe} / \mathrm{L}$.

All ingredients and supplements for cell culture media were obtained from Gibco (Rockville, MD). The cells were used in the Fe uptake experiment at 13 days post seeding. In these conditions, the amount of cell protein measured in each well was highly consistent between wells. In experiment day, $1.5 \mathrm{~mL}$ of the digested sample was added to the insert's upper chamber and incubated for $2 \mathrm{~h}$. Then, inserts were removed and $1 \mathrm{~mL}$ of MEM was added. Cell cultures were incubated for $22 \mathrm{~h}$ at $37^{\circ} \mathrm{C}$.

\section{Harvesting of Caco-2 cells for ferritin analysis}

The protocols used in the ferritin and total protein contents analyses of Caco- 2 cells were similar to those previously described $[8,29,9,28,30]$.

Briefly, growth medium was first removed from the culture well by aspiration and the cells were washed twice with a solution containing $140 \mathrm{mmol} / \mathrm{L} \mathrm{NaCl}, 5 \mathrm{mmol} / \mathrm{L}$ $\mathrm{KCl}$, and $10 \mathrm{mmol} / \mathrm{L}$ PIPES at $\mathrm{pH}$ 7.0. The cells were harvested by adding an aliquot of deionized water and placing them in a sonicator (Lab-Line instruments, Melrose Park, IL). The ferritin and total protein concentrations were determined on an aliquot of the harvested cell suspension with a one-stage sandwich immunoradiometric assay (FER-IRON II Ferritin assay, Ramco laboratories, Houston, TX) and a colorimetric assay (Bio-Rad DC Protein assay, Bio-Rad, Hercules, CA), respectively.

Caco-2 cells synthesize ferritin in response to increases in intracellular iron concentration. Therefore, we used the ratio of ferritin/total protein (expressed as ng ferritin/mg protein) as an index of the cellular Fe uptake. All glassware used in the sample preparation and analyses was acid washed.

\section{In-vivo (intra amniotic administration procedure) bioavailability analysis \\ Birds, diets, and study design}

One hundred and sixty Cornish-cross fertile broiler eggs were obtained from a commercial hatchery (Moyer's chicks, Quakertown, PA), from a maternal flock 35 weeks 
in lay. The eggs were incubated under optimal conditions at the Cornell University Animal Science poultry farm incubator.

\section{Intra-amniotic administration}

The intra amniotic administration procedure was previously described [9,31]. Briefly, at 17 days of embryonic incubation, eggs containing viable embryos $(n=150)$ were weighed and divided into 13 groups $(n=12)$, each with an average egg weight of $49 \pm 1.15 \mathrm{~g}$.

All treatment groups were assigned eggs of similar weight-frequency distribution.

A group of 144 eggs was then injected with the specified solution (1 ml per egg) with a 21-gauge needle into the amniotic fluid, which was identified by candling [31]. The intra-amniotic treatment solution included the following: 'Control 1': non injected eggs; 'Control 2': inulin solution (4\%-inulin/ddH2O); 'Control 3': arabinose solution (4\%-arabinose/ddH2O) and 10 samples (extracted in $\mathrm{ddH} 2 \mathrm{O}$ ).

'Control 1' $(\mathrm{n}=12)$ was non injected group that paralleled routine procedures in commercial hatcheries. After all the eggs were injected, the injection holes were sealed with cellophane tape and the eggs placed in hatching baskets such that each treatment was equally represented at each incubator location.

Hatchability was similar in all treatment groups and was approximately $90 \%$. Immediately after hatch $(21 \mathrm{~d})$ and from each treatment group, 10 chicks were euthanized by carbon dioxide exposure. The digestive tracts and livers were quickly removed from the carcass and separated into various sections for tissue (small intestine and liver 1-2 cm; 2-3gr, respectively) and cecum.

Samples were collected for relative mRNA abundance of intestinal Fe related transporters, relative liver ferritin amounts and bacterial analysis of cecal content, respectively. The samples were immediately frozen in liquid nitrogen, and then stored in a $-80^{\circ} \mathrm{C}$ freezer until analysis. All animal protocols were approved by the Cornell University Institutional Animal Care and Use Committee.

\section{Blood analysis and hemoglobin $(\mathrm{Hb})$ measurements} Blood samples were collected weekly from the wing vein $(\mathrm{n}=10, \sim 50 \mu \mathrm{L})$ using micro-hematocrit heparinized capillary tubes (Fisher, Pittsburgh, PA). Samples were collected immediately after hatch. Blood $\mathrm{Hb}$ concentrations were determined spectrophotometrically using the cyanmethemoglobin method (H7506-STD, Pointe Scientific Inc. Canton, MI) following the kit manufacturer's instructions.

\section{Isolation of total RNA}

Total RNA was extracted from $30 \mathrm{mg}$ of the duodenal tissue (tissue was harvested from the proximal duodenum, $\mathrm{n}=10$ ) using QiagenRNeasy Mini Kit (RNeasy Mini Kit, QiagenInc.,Valencia, CA) according to the manufacturer's protocol. Briefly, tissues were disrupted and homogenized with a rotor-stator homogenizer in buffer $\mathrm{RLT}^{\circ}$, containing $\beta$-mercaptoethanol. The tissue lysate was centrifuged for 3 minutes at $8,000 \mathrm{~g}$ in a micro centrifuge. An aliquot of the supernatant was transferred to another tube, combined with 1 volume of $70 \%$ ethanol and mixed immediately.

Each sample $(700 \mu \mathrm{L})$ was applied to an RNeasy mini column, centrifuged for $15 \mathrm{~s}$ at $8000 \mathrm{~g}$, and the flow through material was discarded. Next, the RN easy columns were transferred to new 2-mL collection tubes, and $500 \mu \mathrm{L}$ of buffer $\mathrm{RPE}^{\circ}$ was pipetted onto the RNeasy column followed by centrifugation for $15 \mathrm{~s}$ at $8000 \mathrm{~g}$. An additional $500 \mu \mathrm{L}$ of buffer RPE were pipetted onto the RNeasy column and centrifuged for 2 min at $8000 \mathrm{~g}$.

Total RNA was eluted in $50 \mu \mathrm{L}$ of RNase free water. All steps were carried out under RNase free conditions. RNA was quantified by absorbance at A 260/280. Integrity of the $28 \mathrm{~S}$ and $18 \mathrm{~S}$ ribosomal RNAs was verified by $1.5 \%$ agarose gel electrophoresis followed by ethidium bromide staining.

DNA contamination was removed using TURBO DNase treatment and removal kit from AMBION (Austin, TX, USA).

\section{DMT1, DcytB and Ferroprtin gene expression analysis}

As previously described $[8,29,32,9]$, briefly, PCR was carried out with primers chosen from the fragment of the chicken (Gallus gallus) duodenal DMT1 gene (GeneBank database; GI 206597489) (forward: 5'-AGC CGT TCA CCA CTT ATT TCG-3'; reverse: 5'-GGT CCA AAT AGG CGA TGC TC-3'), DcytB gene (GI 20380692) (forward: 5'-GGC CGT GTT TGA GAA CCA CAA TGT T-3'; reverse: 5'-CGT TTG CAA TCA CGT TTC CAA AGA T-3') and Ferroportin gene (GI 61098365) (forward: 5'-GAT GCA TTC TGA ACA ACC AAG GA'; reverse: 5'-GGA GAC TGG GTG GAC AAG AAC TC-3'). Ribosomal 18S was used to normalize the results (GI 7262899) (forward: 5'- CGA TGC TCT TAA CTG AGT-3'; reverse: 5'-CAG CTT TGC AAC CAT ACT C-3').

Determination of the linear phase of the PCR amplification was performed (Access RT-PCR system, Promega, Madison, WI) with pooled aliquots removed at 15, 20, $25,30,35,40,45,50$, and 55 cycles.

Amplification of the chicken duodenal DMT1, DcytB and Ferroportin genes were performed for 32, 40 and 30 cycles respectively, which consisted of denaturation $\left(95^{\circ} \mathrm{C}, 30 \mathrm{~s}\right)$, annealing $\left(48^{\circ} \mathrm{C}, 1 \mathrm{~min}\right)$,

and extension $\left(72^{\circ} \mathrm{C}, 1 \mathrm{~min}\right)$; ribosomal $18 \mathrm{~S}$ was amplified at 32 cycles under identical conditions in a different tube. All PCR products were separated by electrophoresis on $2 \%$ agarose gel, stained with ethidium bromide, and 
quantified using the Quantity One 1-D analysis software (Bio-Rad, Hercules, CA).

\section{Ferritin and $\mathrm{Fe}$ in the liver}

Liver samples were treated as described by Mete et al. [33]. Briefly, $1 \mathrm{~g}$ of sample was diluted into $1 \mathrm{~mL}$ of $50 \mathrm{mM}$ Hepes buffer, $\mathrm{pH} 7.4$, and homogenized on ice at $5000 \mathrm{~g}$ and for $2 \mathrm{~min}$. One $\mathrm{mL}$ of each homogenate was subjected to heat treatment for $10 \mathrm{~min}$ at $75^{\circ} \mathrm{C}$ to aid isolation of ferritin since other proteins are not stable at that temperature $[33,34,32,9]$. After heat treatment the samples were immediately cooled down on ice for $30 \mathrm{~min}$.

Thereafter, samples were centrifuged at $13000 \mathrm{~g}$ for $30 \mathrm{~min}$ at $4^{\circ} \mathrm{C}$ until a clear supernatant was obtained and the pellet containing most of the insoluble denaturated proteins was discarded. All tests were conducted in duplicates for each animal $(n=6)$.

\section{Electrophoresis, staining and measurement of gels}

Native polyacrylamide gel electrophoresis was conducted using a $6 \%$ separating gel and a 5\% stacking gel. Samples were run at a constant voltage of $100 \mathrm{~V}$. After electrophoresis, the gels were treated with either of the two stains: Coomasie blue G-250 stain, specific for proteins, or potassium ferricyanide $(\mathrm{K} 3 \mathrm{Fe}(\mathrm{CN}) 6)$ stain, specific for iron.

The corresponding band found in the protein and iron stained gel was considered to be ferritin [32,35,33,34]. The gels were scanned with Bio-Rad densitometer. Measurements of the bands were conducted using the Quantity-One 1-D analysis program (Bio-Rad, Hercules, CA). The local background was subtracted from each sample.

Horse spleen ferritin (Sigma Aldrich Co., St. Louis, MO) was used as a standard for calibrating ferritin protein and iron concentrations of the samples. Dilutions of the horse spleen ferritin were made and treated similarly to the liver supernatant samples in order to create a reference line for both protein and iron-stained gels. Iron levels were determined using the same calibration since approximately $20 \%$ of the weight of horse spleen ferritin is iron.

Saturation levels of ferritin with iron were calculated as the percentage of the iron present in the protein to the maximum amount of iron atoms (4500 iron atoms/ ferritin molecule) ferritin can incorporate [32,35,33,34].

\section{Collection of microbial samples and DNA isolation}

The cecum was removed and treated as described previously (Zhu et al., 2002; Tako et al., 2008; Tako and Glahn, 2012). The contents of the cecum were squeezed out into a sterile $50-\mathrm{mL}$ tube containing $9 \mathrm{~mL}$ of sterile PBS and homogenized by vortexing with glass beads (3- $\mathrm{mm}$ diameter) for $3 \mathrm{~min}$.
Debris was removed by centrifugation at $700 \times \mathrm{g}$ for $1 \mathrm{~min}$, and the supernatant was collected and centrifuged at $12,000 \times \mathrm{g}$ for $5 \mathrm{~min}$. The pellet was washed twice with PBS and stored at $-20^{\circ} \mathrm{C}$ until DNA extraction. For DNA purification, the pellet was resuspended in $50 \mathrm{mM}$ EDTA and treated with lysozyme (Sigma Aldrich Co., St. Louis, MO; final concentration of $10 \mathrm{mg} / \mathrm{mL}$ ) for $45 \mathrm{~min}$ at $37^{\circ} \mathrm{C}$. The bacterial genomic DNA was isolated using a Wizard Genomic DNA purification kit (Promega Corp., Madison, WI). The DNA concentration was determined spectrophotometrically.

\section{Primer design and PCR amplification of bacterial 16S rDNA}

Primers for Lactobacillus (forward: 5'- CAT CCA GTG CAA ACC TAA GAG-3'; reverse: 5'- GAT CCG GTG CAA ACC TAA GAG-3') and Bifidobacterium (forward: 5'- GGG TGG TAA TGC CGG ATG-3'; reverse: 5'CCA CCG TTA CAC CGG GAA-3') were designed according to previously published data [36-38,9,35]. Universal primers identifying all known bacteria were designed using the invariant region in the $16 \mathrm{~s} \mathrm{rDNA}$ of the bacteria (forward: 5'- CGT GCC AGC CGC GGT AAT ACG -3'; reverse: 5'- CGT GCC AGC CGC GGT AAT ACG-3'). The universal primer set was used for determining the total microflora population. For PCR amplification of the bacterial targets from cecal contents, $5 \mu \mathrm{L}$ of DNA extract was added to $45 \mu \mathrm{L}$ of PCR mixture containing $27.5 \mu \mathrm{L}$ of nuclease-free water, $5 \mu \mathrm{L}$ of each primer $(10 \mu \mathrm{g} / \mathrm{mL})$, $1.5 \mu \mathrm{L}$ of nucleotide (dNTP) mix, $5 \mu \mathrm{L}$ of PCR buffer, and $1 \mu \mathrm{L}$ of Taq polymerase (Go-Taq, Promega). The PCR thermal conditions were as follows: 1 cycle of $94^{\circ} \mathrm{C}$ for $3 \mathrm{~min}, 35$ cycles of $94^{\circ} \mathrm{C}$ for $30 \mathrm{~s}, 60^{\circ} \mathrm{C}$ for $1 \mathrm{~min}, 68^{\circ} \mathrm{C}$ for $2 \mathrm{~min}$, and finally $1 \mathrm{cycle}$ of $68^{\circ} \mathrm{C}$ for $7 \mathrm{~min}$. The PCR reaction was run with different numbers of cycles $(25,30,35$, 40,45 , or 50 ) for each primer set, and 35 cycles was in the center of the exponential increase in PCR products.

The PCR products were separated by electrophoresis on $2 \%$ agarose gel, stained with ethidium bromide, and quantified using a Gel-Pro analyzer version 3.0 (Media Cybernetics, Bethesda, MD). To evaluate the relative proportion of each examined bacteria, all products were expressed relative to the content of the universal primer product and proportions of each bacterial group are presented, where the total of the examined bacteria was set at $100 \%$.

\section{Statistical analysis}

Results were analyzed by one way ANOVA using the SPSS statistical software (SPSS 17.0; SPSS Inc, Chicago, IL). Differences between treatments were compared by Tukey's test and significance level of $\mathrm{p}<0.05$ was used for all comparisons. Values in the text are means \pm SD. 


\section{Results and discussion}

The content of prebiotics and phytate and the concentration of micronutrients in wheat samples

Among the $\mathrm{DH}$ lines there were samples with similar levels of phytate and the content of fructans plus arabinoxylans varying from $7.7 \%$ to $10.6 \%$ (Table 1 ).

To examine the effect of prebiotics from processed wheat (and compare them with prebiotic effects of raw material) two commercially bought flour samples were included in this study (Laucke's white and wholemeal flour). These samples contained lower amounts of fructans and arabinoxylans $(3.2 \%$ and $5.8 \%$ fructan plus arabinoxylan), but also much lower levels of phytates. In order to get a better insight into the prebiotic efficacy of baked products we tested the samples of leavened white and wholemeal yeast bread, and chapatti bread.

Yeast leavened breads are most frequently consumed breads in Western countries, while chapatti is the most common type of unleavened wheat bread consumed in Asia. In Pakistan, for example, more than $70 \%$ of the total wheat produced is used to make chapattis [39]. Baked samples of yeast leavened breads contained lower levels of phytate (phytate is degraded during bread baking processes, from $50 \%$ to $90 \%$ ), and lower levels of prebiotics (30\%, fructan reduction, no changes in the content of arabinoxylans), when compared with their corresponding flour samples (Table 1).

There were similar amounts of arabinoxylan, fructan and phytate in the flour and their analogous chapatti breads. The concentrations of micronutrients were lowest in white flour samples and highest in $\mathrm{DH}$ line samples.

\section{In vitro bioavailability results}

The quality controls of in vitro study (ie. cell baseline, $\mathrm{FeCl} 3, \mathrm{FeCl} 3+\mathrm{AA}$ ) were all within the expected and relative ranges which indicate a valid and functional run of the bioassay. As predicted, the results showed improved
Fe bioavailability in the presence of white and wholemeal flour and bread samples (Figure 1). The inhibitory effect of phytate on Fe bioavailability is well known $[40,41]$. Therefore, the lower amounts of phytate in white and wholemeal samples (compared to DH lines) are most likely responsible for observed enhanced Fe bioavailability.

The results of this study confirm previous research $[42,30]$ that reduction of phytate increases iron bioavailability in Caco-2 cells and one would expect enhanced availability if tested in the animal gut. Wheat grains contain endogenous phytase, an enzyme that can release covalently bound phosphate groups from the inositol ring, thus reducing the anti-nutritional effect of phytic acid [43].

These enzymes act by hydrolysing phytic acid into lower myo-inositol phosphate esters with a lower capacity to bind minerals [44]. The fermentation process provides the optimal conditions for phytase activity.

During conversion of flour into bread, phytate content decreases as a consequence of the activity of native phytase. However, as shown in this study the phytate is not reduced to an extent as to greatly improve Fe bioavailability in whole-wheat products. Different factors determine the reduction of phytate content during baking processes such as phytase activity, dough $\mathrm{pH}$, presence of calcium salts and the degree of flour extraction [45].

The essential factor that determines the bioavailability of a compound is the release and solubility of the compound from the food matrix [42]. Even so, relative to controls, bioavailability values of all wheat samples examined in this study were low. Based on previous research, we can assume that such low values (ie. close to baseline, or below) are due to the presence of inhibitors, in this case phytate. However, it should be noted that Fe availability of wheat products is not affected entirely by phytic acid concentration and that other components of

Table 1 The content of prebiotics (arabinoxylans and fructans) and phytate, and the concentration of micronutrients (zinc, iron, phosphorous) in various flour and bread samples

\begin{tabular}{|c|c|c|c|c|c|c|}
\hline Sample & $\mathrm{AX}(\%)$ & Fructan (\%) & Phytate (\%) & $\mathrm{Zn}(\mathrm{mg} / \mathrm{kg})$ & $\mathrm{Fe}(\mathrm{mg} / \mathrm{kg})$ & $P(\mathrm{mg} / \mathrm{kg})$ \\
\hline $\mathrm{DH}$ line number 7 & $7.9 \pm 0.01$ & $2.7 \pm 0.03$ & $1.49 \pm 0.01$ & 28 & 41 & 4200 \\
\hline DH line number 121 & $5.8 \pm 0.04$ & $1.9 \pm 0.01$ & $1.41 \pm 0.03$ & 29 & 47 & 4300 \\
\hline DH line number 114 & $5.8 \pm 0.10$ & $3.2 \pm 0.05$ & $1.29 \pm 0.04$ & 25 & 39 & 3800 \\
\hline DH line number 150 & $7.2 \pm 0.03$ & $0.9 \pm 0.03$ & $1.15 \pm 0.01$ & 25 & 36 & 3800 \\
\hline Crusty white bread mix flour & $1.7 \pm 0.11$ & $1.5 \pm 0.05$ & $0.19 \pm 0.03$ & 6.9 & 11 & 1150 \\
\hline White yeast leavened bread & $1.6 \pm 0.06$ & $0.6 \pm 0.38$ & $0.01 \pm 0.02$ & 8.2 & 12 & 1330 \\
\hline White chapatti bread & $1.5 \pm 0.03$ & $1.5 \pm 0.14$ & $0.15 \pm 0.04$ & 14 & 19 & 1700 \\
\hline Wholemeal bread mix flour & $3.8 \pm 0.03$ & $2.0 \pm 0.20$ & $0.72 \pm 0.01$ & 18 & 33 & 2600 \\
\hline Wholemeal yeast leavened bread & $3.9 \pm 0.06$ & $1.0 \pm 0.38$ & $0.37 \pm 0.03$ & 20 & 37 & 3000 \\
\hline Wholemeal chapatti bread & $3.5 \pm 0.26$ & $1.9 \pm 0.34$ & $0.64 \pm 0.03$ & 19 & 34 & 2800 \\
\hline
\end{tabular}

Values are means $+/-S D(n=4) . A X=$ arabinoxylan. 


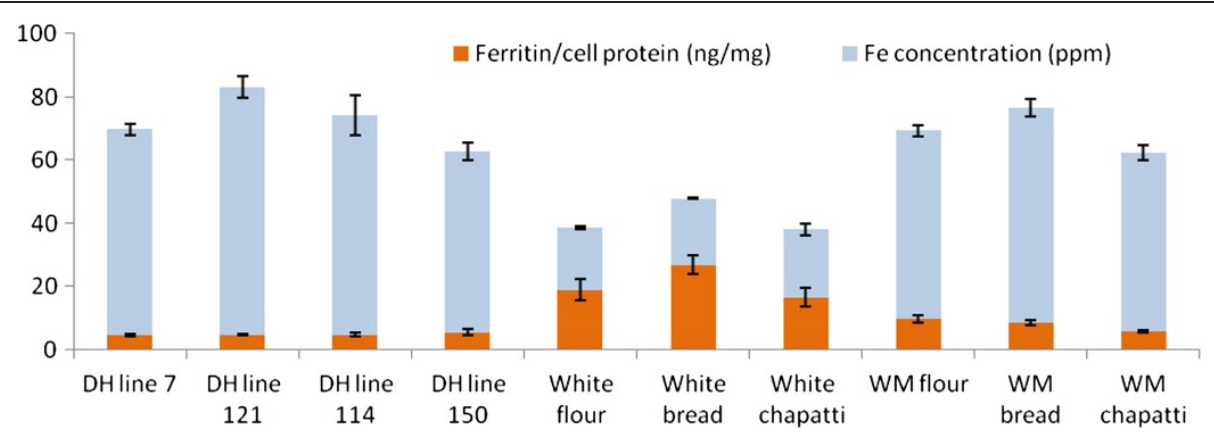

Figure 1 Summary of in vitro bioavailability results. Red columns - Ferritin concentrations in Caco-2 cells exposed to samples (ng of ferritin/ $\mathrm{mg}$ of protein). Values are means $+/-\mathrm{SD}(\mathrm{n}=6), \mathrm{P}<0.05$. Blue columns - Sample Fe concentration (means $+/-\mathrm{SD}(\mathrm{n}=3), \mathrm{P}<0.05, \mathrm{ppm})$. WM $=$ wholemeal.

wheat grains and bakery products may also have an effect on iron availability; i.e. proteins, calcium [42].

\section{In vivo bioavailability results (DMT1, DcytB, ferroportin, liver ferritin, $\mathrm{Hb}$ )}

There were no significant differences in Fe bioavailability between treatment diets for hemoglobin (Table 2).

Similarly, no significant variations were observed in the intestinal expression of DMT1, Ferroportin (major intestinal Fe transporters) and DcytB (Fe reductase). The relative liver ferritin amounts between the treatment groups were also not different. One possible explanation is the amount of material that was administrated in-ovo, as we were limited by the osmolality of the injected solution (not more than 3200SM, as embryonic dehydration will occur).

Another reason could be the duration of the study; it was a short term (one time administration) study, which may not be long enough time to observe the efficacy of these particular treatments on Fe bioavailability measures. Similar to previous studies, the poultry $[29,9]$ and Caco-2 cell $[28,30]$ models are sensitive and responsive to bioavailable Fe.

In conclusion, the in vivo results are in agreement with the in vitro observations showing no differences in the hatchling Fe status between the treatment groups.

Bacterial populations in the intestinal content of chickens Overall, there was a significant increase in the relative amounts of bifidobacteria and lactobacilli in intestinal content between the treatments groups (Figure 2). Considerably more bifidobacteria has been produced in the presence of most samples (exception is white flour sample where there were no statistically significant differences in the production of bifidobacteria and lactobacilli).

Making individual comparisons, there were no statistically significant differences in both lactobacilli and bifidobacteria production between DH line treatments. As expected, due to the higher amounts of prebiotics present (difference in prebiotic content up to $7.4 \%$ ) there were significantly higher production of bacteria in the presence of DH line treatments compared to the

Table 2 Blood hemoglobin $(\mathrm{Hb})$ concentration $(\mathrm{g} / \mathrm{dL})$, liver ferritin protein amounts, and duodenal mRNA abundance of DMT1, Dcytb and ferroportin in broiler chickens fed with different flour and bread samples

\begin{tabular}{lccccc}
\hline Sample & Blood Hb & Liver ferritin & Dcytb & DMT1 & Ferroportin \\
\hline DH line number 7 & $10.22 \pm 1.40$ & $0.56 \pm 0.02$ & $0.65 \pm 0.04$ & $0.75 \pm 0.05$ & $0.69 \pm 0.02$ \\
DH line number 121 & $11.31 \pm 1.40$ & $0.56 \pm 0.02$ & $0.65 \pm 0.04$ & $0.75 \pm 0.04$ & $0.68 \pm 0.04$ \\
DH line number 114 & $10.50 \pm 1.65$ & $0.55 \pm 0.04$ & $0.65 \pm 0.03$ & $0.75 \pm 0.04$ & $0.68 \pm 0.03$ \\
DH line number 150 & $10.91 \pm 2.05$ & $0.56 \pm 0.03$ & $0.65 \pm 0.02$ & $0.76 \pm 0.04$ & $0.69 \pm 0.02$ \\
Crusty white bread mix flour & $10.64 \pm 1.79$ & $0.55 \pm 0.03$ & $0.65 \pm 0.03$ & $0.76 \pm 0.03$ & $0.69 \pm 0.03$ \\
White yeast leavened bread & $11.13 \pm 1.50$ & $0.55 \pm 0.03$ & $0.65 \pm 0.04$ & $0.76 \pm 0.04$ & $0.69 \pm 0.03$ \\
White chapatti bread & $11.59 \pm 0.88$ & $0.55 \pm 0.04$ & $0.66 \pm 0.05$ & $0.76 \pm 0.04$ & $0.69 \pm 0.04$ \\
Wholemeal bread mix flour & $11.32 \pm 1.39$ & $0.55 \pm 0.03$ & $0.66 \pm 0.03$ & $0.75 \pm 0.03$ & $0.69 \pm 0.03$ \\
Wholemeal yeast leavened bread & $11.59 \pm 1.36$ & $0.56 \pm 0.02$ & $0.65 \pm 0.04$ & $0.76 \pm 0.03$ & $0.69 \pm 0.03$ \\
Wholemeal chapatti bread & $10.61 \pm 0.89$ & $0.56 \pm 0.04$ & $0.65 \pm 0.04$ & $0.76 \pm 0.02$ & $0.69 \pm 0.02$ \\
\hline
\end{tabular}

Changes in mRNA abundance are expressed relative to the expression of 18S rRNA in arbitrary units (AU). Values are means $+/-$ SD $(n=10)$. 


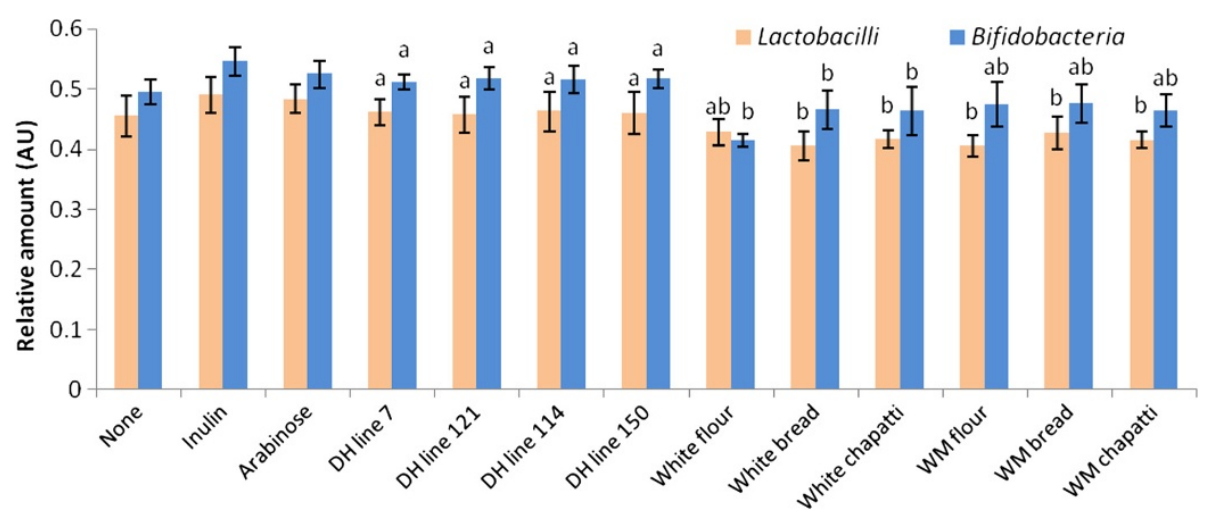

Figure 2 The relative amounts of Lactobacilli and Bifidobacteria generas in intestinal contents of chickens expressed in arbitrary units (AU). Values are means $+/-S D(n=10)$. a, b Mean values within each bacterial species tested with unlikesuperscript letters are significantly different $(p<0.05)$.

treatments with commercially produced white and wholemeal flour samples $(\mathrm{p}<0.01)$.

There were statistically significant difference in expansion of bacteria between the wholemeal and white flour (wholemeal more bifidobacteria, white more lactobacillus) $(\mathrm{p}=0.02 ; \mathrm{p}=0.04$, respectively).

Additionally, there were no discrepancies in lactobacillus production among the treatments of white and wholemeal flour and their corresponding baked products.

In the presence of white flour baked products, more bifidobacteria was produced in the white flour treatment $(\mathrm{p}<0.003)$; while there were no changes in production of bifidobacteria between the wholemeal flour and corresponding baked products. Finally, there were no variations in bacterial production between the white and wholemeal breads.

In conclusion, prebiotic segments of wheat enhanced the growth of colon microflora, with generally more bifidobacteria being formed. This is an important finding as these bacterial populations may affect Fe bioavailability and improve gut health.

Our findings are concurring with previously published papers that demonstrate an increase in bifidobacteria population in the ceca in the presence of inulin $[29,46,47]$. Some recently completed human trials clearly show the association between the production of gut bacteria and Fe absorption.

In Fe-deficient young women in South India lower levels of lactobacilli were measured which suggest that bacterial flora have an important role in the Fe absorption process [48]. In addition, it has been demonstrated that bifidobacteria have a nutritional advantage compared with other intestinal microorganisms due to their $\beta-1,2-$ glycosidase activity $[49,7]$.

As mentioned earlier, one of the possible reasons for increased mineral bioavailability in the presence of prebiotics is that they serve as a substrate for short chain fatty acid (SCFA) synthesis and as a consequence of SCFA production, more of the "beneficial bacterial community" is formed which further enhances the absorption of minerals (such as $\mathrm{Ca}, \mathrm{Zn}$ and $\mathrm{Fe}$ ) in the colon $[12,13,50]$. SCFA positively affect Fe bioavailability by releasing Fe from complexes by a lowering of the $\mathrm{pH}$. The lowering of the $\mathrm{pH}$ enhances mineral absorption by releasing the iron from protein complexes [51]. Furthermore, one of the fermentation products, propionate, can create soluble complexes with $\mathrm{Fe}$ and consequently make the $\mathrm{Fe}$ more absorbable [51].

In addition, SCFAs can enlarge the absorption area through stimulation of the epithelial cells to proliferate. Lactobacilli and Bifidobacteria are beneficial for humans with low Fe status as bioavailability of Fe is improved as a result of the reduction in the amounts of the pathogenic becteria using dietary Fe [52].

In-vitro data show that more bioavailable Fe has been measured in the presence of samples containing lower levels of phytate. However, high amounts of phytate in samples were not a limiting factor for the stimulation of beneficial gut microbiata production. Generally speaking, the production of beneficial bacteria was higher in the presence of samples with higher amounts of prebiotics (wholemeal flour and bread samples) which clearly demonstrates that the consumption of wholemeal bread as opposed to white bread is not a contributing factor in the development of Fe deficiency. Similarly, the baking process (including the fermentation) does not seem to have a crucial role in microbial production as there were no discrepancies in bacterial production among the treatments of white and wholemeal flour and their corresponding baked products.

It has been shown that both bifidobacteria and lactobacilli can produce phytate degrading enzymes [53]. It seems that prebiotics influence the production of probiotics which degrades the phytate via the action of 
phytate degrading enzymes and in this way may positively influence Fe absorption.

Previously, we have been able to show the change of receptors of $\mathrm{Fe}$ in different places of the intestine in pigs and chickens in the presence of prebiotics $[8,9]$. However, even with those studies, it sometimes took more than six weeks to observe the changes in all Fe related parameters (i.e. the concentration of $\mathrm{Hb}$ ). Therefore, we believe that further improvement of Fe status in vivo (i.e. changes in Fe related proteins and enzymes) in the presence of wheat products may be seen in a longer term study.

\section{Conclusion}

Iron deficiency is the most prevalent nutritional deficiency worldwide. At present, there is more and more interest in improving gut health, and consequently increasing Fe absorption, by managing the colonic microbial population.

This study demonstrated that prebiotics naturally found in wheat grains/bread products significantly increased intestinal beneficial bacterial population in Fe deficient broiler chickens. The prebiotic segments of wheat enhanced the growth of colon microflora, with generally more bifidobacteria being created. This is an important finding as formed bacterial populations improve gut health and can consequently contribute to increased Fe absorption. With this short-term feeding trial we were not able to show differences in the Fe-status of broilers. Nevertheless, the bacterial analysis clearly suggests that we may have more significant differences (i.e. increased Fe bioavailability and improved Fe status) in a longer term feeding trial. Based on the results presented here, additional in-vitro and in-vivo trials are required to increase our knowledge on the nutritional and essential prebiotic properties of wheat grains and their baked products in improving Fe absorption.

\section{Abbreviations}

Fe: Iron; Hb: Hemoglobin; Hb: Fe, hemoglobin iron; AX: Arabinoxylan; FOS: Fructooligosacharides; DH: Double haploid; SCFA: Short chain fatty acids; mRNA: Messenger ribonucleic acid; QTL: Quantitative trait loci; HPLC: High performance liquid chromatography; PCR: Polymerase chain reaction; DMT-1: Divalent metal transporter 1; DcytB: Duodenal cytochrome B; MEM: Minimum essential media.

\section{Competing interests}

All of the authors read and approved the final version of the manuscript. None of the authors had a conflict of interest.

\section{Authors' contributions}

ET carried out the in vivo study, analyzed and interpreted data and helped to draft the manuscript, co-authored the paper. RG was responsible for in vitro study; reviewed the final draft of the manuscript. MK carried out preparation of bread samples and completed sugar and phytate analysis, evaluated data, wrote the manuscript and prepared the manuscript for submission to the journal. JS responsible for the design of the study, organization of micronutrient analysis, reviewed the final draft of the manuscript, co-authored the paper. All authors read and approved the final manuscript.

\section{Acknowledgments}

We thank HarvestPlus for funding the micronutrient and phytate analysis. The Waite Analytical Service for micronutrient analysis and Dr Hugh Wallwork (PIRSA-SARDI) for supply of the Berkut $x$ Krichauff double haploid wheat seed.

\section{Author details}

'USDA/ARS, Robert W. Holley Centre for Agriculture and Health, Cornell University, Ithaca, NY 14853, USA. ${ }^{2}$ School of Biological Sciences, Flinders University, GPO Box 2100, Adelaide, SA 5001, Australia.

Received: 7 January 2014 Accepted: 5 June 2014

Published: 13 June 2014

\section{References}

1. Muthayya S, Rah JH, Sugimoto JD, Roos FF, Kraemer K, Black RE: The global hidden hunger indices and maps: an advocacy tool for action. PLoS One 2013, 8:7860.

2. WHO: Worldwide Prevalence of Anaemia 1993-2005. WHO Global Database on Anaemia. Geneva: World Health Organization; 2008.

3. FAO: Cereals and other starch-based staples: are consumption patterns changing? 2010. Available from: http://www.fao.org/docrep/meeting/007/ j1183e/j1183e00.htm.

4. Brigide P, Canniatti-Brazaca SG: Antinutrients and "in vitro" availability of iron in irradiated common beans (Phaseolus vulgaris). Food Chem 2006, 98:85-89.

5. Lehrfeld J: High-performance liquid chromatography analysis of phytic acid on a pH-stable, macroporous polymer column. Cereal Chem 1989, 66:510-515.

6. Ohta A, Ohtsuki M, Uehara M, Hosono A, Hirayama M, Adachi T, Hara H: Dietary fructooligosaccharides prevent postgastrectomy anemia and osteopenia in rats. J Nutr 1998, 128:485-490.

7. Van de Wiele T, Boon N, Possemiers S, Jacobs H, Verstraete W: Inulin-type fructans of longer degree of polymerization exert more pronounced in vitro prebiotic effects. J Appl Microb 2007, 102:452-460.

8. Tako E, Hoekenga OA, Kochian LV, Glahn RP: High bioavailablilty iron maize (Zea mays L.) developed through molecular breeding provides more absorbable iron in vitro (Caco-2 model) and in vivo (Gallus gallus). Nutr J 2013, 12:3.

9. Tako E, Welch RM, Lei X, Yasuda K, Miller DD: Dietary inulin affects the expression of intestinal enterocyte iron transporters, receptors and storage protein and alters the microbiota in the pig intestine. $\mathrm{Br} J$ Nutr 2008, 99:472-480.

10. Teitelbaum JE, Walker WA: Nutritional impact of pre- and probiotics as protective gastrointestinal organisms. Ann Rev Nutr 2002, 22:107-138.

11. Wong JMW, de Souza R, Kendall CWC, Emam A, Jenkins DJA: Colonic health: Fermentation and short chain fatty acids. J Cli Gastro 2006, 40:235-243.

12. Delzenne NM, Roberfoird MR: Physiological effects of nondigestible oligosaccharides. Food Sci Technol 1994, 27:1-6.

13. Macfarlane $\mathrm{S}$, Macfarlane GT, Cummings $J \mathrm{H}$ : Review article: prebiotics in the gastrointestinal tract. Ali Pharma Therap 2006, 24:701-714.

14. Tuohy KM, Rouzaud GCM, Bruck WM, Gibson GR: Modulation of the human gut microflora towards improved health using prebiotics assessment of efficacy. Curr Pharm Des 2005, 11:75-90.

15. Yasuda K, Roneker KR, Miller DD, Welch RM, Lei XG: Supplemental dietary inulin affects bioavailability of iron present in corn and soybean meal to young pigs. J Nutr 2006, 136:3033-3038.

16. Sanchez J, Marzorati M, Grootaert C, Baran M, Van Craeyveld V, Courtin CM, Broekaert WF, Delcour JA, Verstraete W, Van de Wiele T: Arabinoxylanoligosaccharides (AXOS) affect the protein/carbohydrate fermentation balance and microbial population dynamics of the simulator of human intestinal microbial ecosystem. Microbial Biotechn 2009, 2:101-113.

17. Fincher $G B$, Stone BA: Cell walls and their components in cereal grain technology. In Advances in Cereal Science and Technology. Edited by Pomeranz Y. St. Paul: American Association of Cereal Chemistry; 1986.

18. Knudsen KEBH, Hunsen I: Gastrointestinal implications in pigs of wheat and oat fractions. 1. Digestibility and bulking properties of polysaccharides and other major constituents. Br J Nutr 1991, 3:223-239.

19. Revanappa SB, Nandini CD, Salimath PV: Structural characterization of pentosans from hemicellulose $B$ of wheat varieties with varying chapati-making quality. Food Chem 2010, 119:27-33. 
20. Campbell JM, Fahey GC, Wolf BW: Selected indigestible oligosaccharides affect large bowel mass, cecal and fecal short-chain fatty acids, $\mathrm{pH}$ and microflora in rats. J Nutr 1997, 127:130-136

21. Durieux A, Fougnies C, Jacobs H, Simon JP: Metabolism of chicory fructooligosaccharides by bifidobacteria. Biotechn Lett 2001, 23:1523-1527.

22. Hsu CK, Liao JW, Chung YC, Hsieh CP, Chan YC: Xylooligosaccharides and fructooligosaccharides affect the intestinal microbiota and precancerous colonic lesion development in rats. J Nutr 2004, 134:1523-1528.

23. Freitas KC, Amancio OM, de Morais MB: High-performance inulin and oligofructose prebiotics increase the intestinal absorption of iron in rats with iron deficiency anaemia during the growth phase. Br J Nutr 2012, 108:1008-1016.

24. Nguyen Van Lam HBL, Wallwork H, Stangoulis JCR: Identification of quantitative trait loci for grain arabinoxylan concentration in bread wheat. Crop Sci 2011, 51:1143-1150.

25. Huynh BL, Mather DE, Wallwork H, Graham RD, Welch RM, Stangoulis JCR: Genotypic variation in wheat grain fructan content revealed by a simplified HPLC method. J Cer Sci 2008, 48:369-378.

26. Zarcinas BA, Cartwright B, Spouncer LR: Nitric acid digestion and multi-element analysis of plant material by inductively coupled plasma spectrometry. Commun Soil Sci Plant Anal 1987, 18:131-146.

27. Vidanarachchi JK, lji PA, Mikkelsen LL, Sims I, Choct M: Isolation and characterization of water-soluble prebiotic compounds from Australian and New Zealand plants. Carbohydr Polym 2009, 77:670-676.

28. Glahn RP, Lee OA, Yeung A, Goldman MI, Miller DD: Caco-2 cell ferritin formation predicts nonradiolabeled food iron availability in an in vitro digestion/Caco-2 cell culture model. J Nutr 1998, 128:1555-1561.

29. Tako E, Glahn RP: White beans provide more bioavailable iron than red beans: Studies in poultry (Gallus gallus) and an in vitro digestion/Caco-2 model. Int J Vitam Nutr Res 2010, 80:416-429.

30. Glahn RP, Wortley GM, South PK, Miller DD: Inhibition of iron uptake by phytic acid, tannic acid, and $\mathrm{ZnCl} 2$ : studies using an in vitro digestion/ Caco-2 cell model. J Agricul Food Chem 2002, 50:390-e395.

31. Tako E, Ferket PR, Uni Z: Effects of in ovo feeding of carbohydrates and $\beta$-hydroxy- $\beta$-methylbutyrate on the development of chicken intestine. Poult Sci 2004, 83:2023-2028.

32. Tako E, Blair MW, Glahn RP: Biofortified red mottled beans (Phaseolus vulgaris L.) in a maize and bean diet provide more bioavailable iron than standard red mottled beans: Studies in poultry (Gallus gallus) and an in vitro digestion/Caco-2 model. Nutr J 2011, 10:113.

33. Mete A, Van Zeeland YR, Vaandrager AB, van Dijk JE, Marx JJ, Dorrestein GM: Partial purification and characterization of ferritin from the liver and intestinal mucosa of chickens, turtledoves and mynahs. Avian Pathol. 2005, 34:430-434.

34. Passaniti A, Roth TF: Purification of chicken liver ferritin by two novel methods and structural comparison with horse spleen ferritin. J Biochem 1989, 258:413-419.

35. Tako E, Glahn RP: Intra-amniotic administration and dietary inulin affect the iron status and intestinal functionality of iron-deficient broiler chickens. Poult Sci 2012, 91:1361-1370.

36. Langendijk PS, Schut F, Jansen GJ, Raangs GC, Kamphuis GR, Wilkinson MHF, Welling GW: Quantitative fluorescence in situ hybridisation of Bifidobacterium spp with genus-specific 16S rRNA-targeted probes and its application in fecal samples. Appl Environ Microbiol 1995, 61:3069-3075.

37. Zhu X, Zhong T, Pandaya Y, Joergert RD: $16 \mathrm{~S}$ rRNA-based analysis of microbiota from the cecum of broiler chickens. Appl Environ Microbiol 2002, 68:124-137.

38. Amit-Romach E, Sklan D, Uni Z: Micro flora ecology of the chicken intestine using 16S ribosomal DNA primers. Poult Sci 2004, 83:1093-1098.

39. Ahmed A, Anjum FM, Rehman S, Randhawa MA, Farooq U: Bioavailability of calcium, iron and zinc fortified whole wheat flour chapatti. Plant Foods Hum Nutr 2008, 63:7-13.

40. Sandberg AS, Hulthen LR, Türk M: Dietary Aspergillus nigerphytase increases iron absorption in humans. J Nutr 1996, 126:476-480.

41. Hurrell RF: Phytic acid degradation as a means of improving iron absorption. Int J Vitam Nutr Res 2004, 74:445-452.

42. Frontela C, Ros G, Martínez C: Phytic acid content and "in vitro" iron, calcium and zinc bioavailability in bakery products: The effect of processing. J Cer Sci 2011, 54:173-179.
43. Gobbetti M, De Angelis M, Corsetti A, Di Cagno R: Biochemistry and physiology of sourdough lactic acid bacteria. Trends Food Sci \& Technol 2005, 16:57-e69.

44. Leenhardt F, Levrat-Verny MA, Chanliaud E, Rémésy C: Moderate decrease of $\mathrm{pH}$ by sourdough fermentation is sufficient to reduce phytate content of whole wheat flour through endogenous phytase activity. J Agri Food Chem 2005, 1:98-e102

45. Türk $M$, Sandberg A: Phytate hydrolysis during bread-making: effect of addition of phytase from Aspergillus nige. J Cer Sci 1992, 15:281-e294.

46. Patterson JK, Yasuda K, Welch RM, Miller DD, Lei X: Supplemental dietary inulin of variable chain lengths alters intestinal bacterial populations in young pigs. J Nutr 2010, 140:2158-61.

47. Rebolé A, Ortiz LT, Rodríguez ML, Alzueta C, Treviño J, Velasco S: Effects of inulin and enzyme complex, individually or in combination, on growth performance, intestinal microflora, cecal fermentation characteristics, and jejunal histomorphology in broiler chickens fed a wheat- and barley-based diet. Poult Sci 2010, 89:276-286.

48. Balamurugan R, Mary RR, Chittaranjan S, Jancy H, Shobana Devi R, Ramakrishna BS: Low levels of faecal lactobacilli in women with irondeficiency anaemia in south India. Br J Nutr 2010, 104:931-934.

49. Hopkins MJ, Macfarlane GT: Nondigestible oligosaccharides enhance bacterial colonization resistance against Clostridium difficile in vitro. App Envirn Microbiol 2003, 69:1920-1927.

50. Lopez HW, Levrat MA, Guy C, Messager A, Demigné C, Rémésy C: Effects of soluble corn bran arabinoxylans on cecal digestion, lipid metabolism, and mineral balance (Ca, Mg) in rats. J Nutr Biochem 1999, 10:500-509.

51. Yeung CK, Glahn R, Welch RM, Miller DD: Prebiotics and iron bioavailability -is there a connection? J Food Sci 2005, 70:R88-R92.

52. Patterson JK, Lei XG, Miller DD: The pig as an experimental model for elucidating the mechanisms governing dietary influence on mineral absorption. Exp Biol Med 2008, 233:651-664.

53. Haros M, Carlsson NG, Almgren A, Alminger ML, Sandberg AS, Andlid T: Phytate degradation by human gut isolated Bifidobacterium pseudocatenulatum ATCC27919 and its probiotic potential. Int J Food Microb 2009, 135:7-14

doi:10.1186/1475-2891-13-58

Cite this article as: Tako et al:: The effect of wheat prebiotics on the gut bacterial population and iron status of iron deficient broiler chickens. Nutrition Journal 2014 13:58.

\section{Submit your next manuscript to BioMed Central and take full advantage of:}

- Convenient online submission

- Thorough peer review

- No space constraints or color figure charges

- Immediate publication on acceptance

- Inclusion in PubMed, CAS, Scopus and Google Scholar

- Research which is freely available for redistribution 